\title{
Plasma Cholesterol and Triglyceride Distributions in 13,665 Children and Adolescents: the Prevalence Study of the Lipid Research Clinics Program
}

\author{
BOBBE CHRISTENSEN, CHARLES GLUECK, PETER KWITEROVICH, IDO DEGROOT, GARY CHASE, \\ GERARDO HEISS, RICHARD MOWERY, ISRAEL TAMIR, AND BASIL RIFKIND ${ }^{(48)}$ \\ Epidemiology Discipline/Disease Control Module, The University of Texas, School of Public Health, Houston, Texas, \\ USA [B. C.J; Department of Internal Medicine, University of Cincinnati, College of Medicine, Cincinnati, Ohio, USA \\ [C. G., I. deG.]; Departments of Pediatrics and Medicine, The Johns Hopkins University School of Medicine, \\ Baltimore, Maryland, USA [P. K., G. C.J; Department of Biostatistics, University of North Carolina, Chapel Hill, \\ North Carolina, USA [G. H., R. M.]; and Lipid Metabolism Branch, National Heart, Lung, and Blood Institute \\ National Institutes of Health, Bethesda, Maryland, USA [1. T., B. R.]
}

\section{Summary}

The age-, race-, and sex-specific distributions for plasma cholesterol (CH) and triglyceride (TG) are described for the 13,655 individuals under 20 years of age who were examined at the first visit (visit I) of the Prevalence Study of the Lipid Research Clinics (LRC) Program. Composite findings are presented from the seven North American LRC's where children were included in the target population. Cholesterol values are higher for blacks than for whites, but triglyceride values are higher for whites than for blacks. In both the $\mathrm{CH}$ and $\mathrm{TG}$ distributions for the combined races, the mean values for females are generally higher than for males. For cholesterol, consistent age-associated differences occur. On average, the $\mathrm{CH}$ values peak in late childhood and decline during adolescence. The decrease in mean values for $\mathrm{CH}$ is most marked for white males. The values for TG tend to increase in early adolescence. This report expands the available information about lipid distributions in young populations and describes the extent of the variation in plasma lipids associated with race and sex for each year of age, 0 to 19 years.

\section{Speculation}

The pattern of age-associated differences found in these population-based, cross-sectional surveys points to the need for prospective studies of lipid levels in cohorts examined before puberty and followed throughout adolescence and into early childhood. Such longitudinal studies may reveal the biological explanation for the age-curve of the mean values for lipids.

\section{INTRODUCTION}

Atherosclerotic cardiovascular disease is the leading cause of morbidity and mortality in the United States and other industrialized countries $(19-21,39,40)$. Atherosclerosis is a chronic disease process which often precedes the clinical manifestations of myocardial infarction, angina pectoris, and stroke. An increasing amount of evidence suggests that the genesis of atherosclerosis is in childhood or adolescence $(2,10,22)$. Primary prevention of atherosclerosis might therefore reasonably begin in the pediatric age group if the etiological factors can be identified and modified in the young. Epidemiological studies in adults have shown that elevated plasma cholesterol, hypertension, and cigarette smoking are especially associated with increased risk for the development of atherosclerotic cardiovascular disease $(5,17)$. The epidemiological evidence that hypertriglyceridemia is a separate risk factor for ischemic heart disease is contradictory $(4,33)$. In some families with inherited hyperlipidemias, however, hypertriglyceridemia without hypercholesterolemia appears to be associated with premature cardiovascular disease (15). Children of persons who have myocardial infarction also tend to have elevated lipids $(11,18,41)$. Plasma lipids are transported by lipoproteins, two classes of which, beta or low-density lipoproteins (LDL) and prebeta or very-lowdensity lipoproteins (VLDL), appear atherogenic $(14,45)$. Recent evidence suggests that the level of alpha or high-density lipoproteins (HDL) is inversely related to risk for cardiovascular disease $(5,17,29)$.

Recently several epidemiological studies have been undertaken to delineate similar "descriptors of risk" in children. As a first step, these surveys provide descriptive information for age-, race-. and sex-specific distributions of these risk factors in the young. From this information base, hypotheses may then be tested during longitudinal follow-up and evaluation.

The Prevalence Study of the LRC Program was designed to provide a significant pediatric component which would encompass population groups of diverse socioeconomic and ethnic composition (26). One-fourth of the persons sampled in the North American component of the LRC study persons were under twenty years of age. The purpose of this report is to describe the distribution of plasma levels of cholesterol and triglycerides in these children and adolescents and to determine age-, race-, and sexassociated differences in the plasma lipid levels as measured during the first examination (Visit I) of the LRC Prevalence Study.

\section{MATERIALS AND METHODS}

\section{STUDY POPULATION}

This report presents the composite findings for subjects 0 to 19 years of age from the seven North American LRC's where studies of children were included in the target populations. Children enrolled in schools were sampled in Houston and Cincinnati. In five other sites (Oklahoma, LaJolla, Minnesota, Toronto, and Baltimore), studies based on industrial populations and their families or samples of households contributed data on children.

Of the 19,479 person $<20$ years of age who were eligible for the visit I component of the LRC Prevalence Study, 15,622 (80.2\%) 
were examined. The analysis for this report includes only the data for examined persons who met the following six criteria: (1) age, in completed years, of $<20$ years; (2) race, classified either as white or black; (3) lipid values based on unfrozen blood samples; (4) not currently taking medication prescribed to reduce blood pressure, blood lipids, blood glucose or uric acid and not taking hormone preparations; (5) not pregnant; and (6) fasting $\geq 12$ hours before examination. Based on these criteria, 1 person was excluded due to an invalid recording of age, 136 persons could not be classified either as white or as black, and 505 exclusions were due to frozen blood samples. From the 14,980 remaining records which met the first three criteria, an additional 1,315 were excluded due to criteria 4, 5, and/or 6 . Although some $(\leq 50)$ individuals were excluded for more than one reason, the number of exclusions for each of the three remaining criteria were as follows: medication use, 306 (to reduce blood pressure, 6; lipids, 2; blood sugar, 23; uric acid, 2; and oral contraceptive use, 280); pregnant or uncertain, 37; and nonfasting, 1,022. Thus, this report is based on the 13,665 persons who met all of the six criteria for inclusion in the analysis.

\section{STUDY DESIGN AND LABORATORY METHODS}

Details of the overall study design of the LRC prevalence studies, including the definitions of the target populations, methods of sampling, and standardization of measurements and procedures are described in reference protocols, laboratory manuals, and other publications of the LRC program (25-27).

During visit 1 , identification and sociodemographic information was obtained, and a blood sample was drawn from persons who had fasted at least $12 \mathrm{hr}$. More detailed examination was performed at a second visit (visit 2 ) in a $15 \%$ randomly selected group from visit 1 and in children who had hyperlipidemia at visit 1 . The results of this second examination, which included measurements of height, weight, blood pressure, lipids and lipoproteins, secondary clinical chemistries, and a family and medical history, will be reported subsequently.

At visit $1,15 \mathrm{ml}$ of blood were drawn into an evacuated tube containing $16 \mathrm{mg}$ of disodium ethylenediaminetetracetic acid. Plasma was prepared within $4 \mathrm{hr}$ by centrifugation at $4^{\circ} \mathrm{C}$ for $45,000 \mathrm{~g}$-min. An isopropanol extract of plasma was prepared and treated with zeolite to remove interfering substances. Total plasma cholesterol and triglyceride concentrations were determined from this extract on either the Autoanalyzer I (Baylor, Johns Hopkins, and LaJolla LRC's) or on the Autoanalyzer II (Cincinnati, Oklahoma, Minnesota, and Toronto) after each of the laboratories had completed the LRC lipid standardization program $(3,29)$. The performance of each laboratory was monitored internally by means of serum pools of known cholesterol and triglyceride values established by reference methods. The precision achieved during

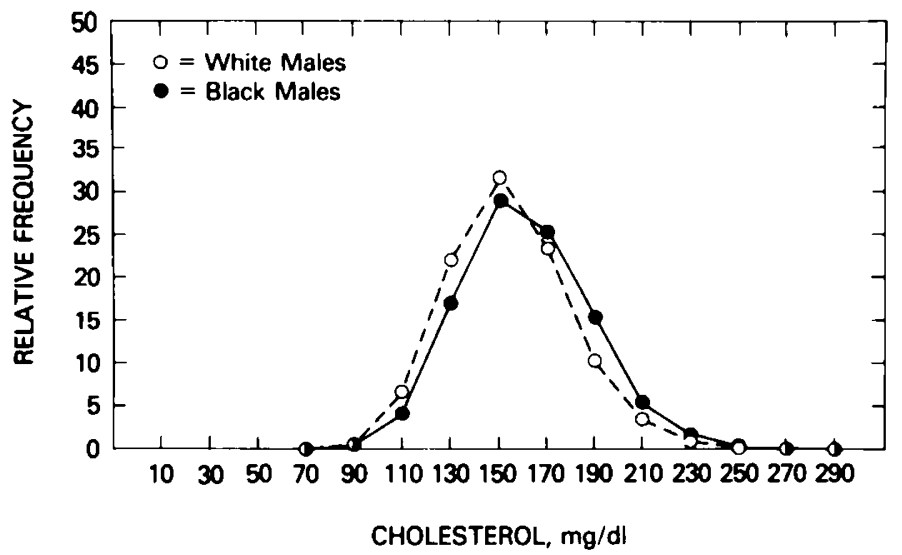

Fig. 1. Percentage of distribution of plasma cholesterol for white and black males. analysis of these internal control pools have been published elsewhere $(1,3,28)$. In addition, the performance of the laboratories was monitored by external quality control during the course of the study. A total of 864 samples from 18 serum pools with concentrations ranging from 59 to $349 \mathrm{mg} / \mathrm{dl}$ for cholesterol and 36 to $274 \mathrm{mg} / \mathrm{dl}$ for triglycerides were analyzed. Criteria for acceptable performance during external surveillance have been published previously $(1,28)$.

\section{METHODS OF ANALYSIS}

The age-specific distributions for cholesterol and triglycerides are examined separately for males and females and for both blacks and whites. Large sample sizes for ages six or greater allowed analysis for the four race-sex groups by single year of age, which revealed patterns that would have been obscured by the use of wider age intervals. When the number in an age, race, and sex group was less than 50 persons, the number is enclosed with brackets in the tables, and selected statistics are presented for completeness of information only. For sample size $\geq 50,5$ th, 10 th 25th, 50th, 75th, 90th, and 95th percentiles were calculated in addition to the mean and standard deviation. Differences in cholesterol and triglyceride distributions by sex and race were tested by a two-sample Kolmogorov-Smirnov statistic (36).

\section{RESULTS}

\section{OVERALL DISTRIBUTIONS}

The relative frequency distributions for plasma cholesterol are presented for white males and black males (Fig. 1) and for white females and black females (Fig. 2). Comparable frequency distri-

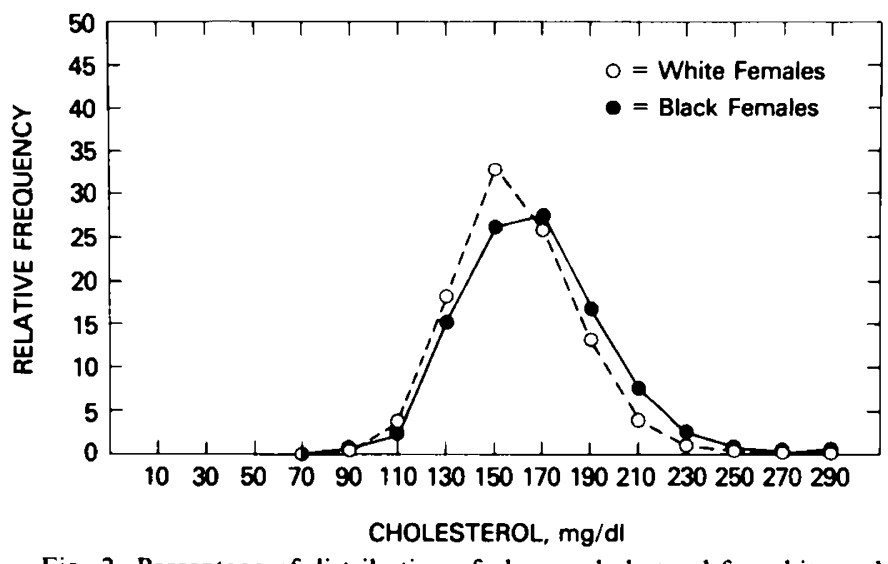

Fig. 2. Percentage of distribution of plasma cholesterol for white and black females.

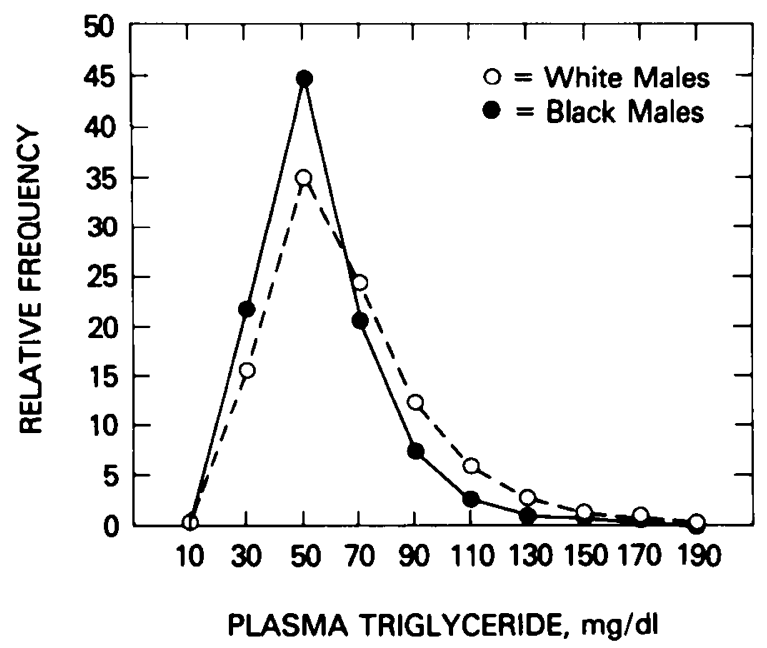

Fig. 3. Percentage of distribution of fasting triglyceride for white and black males. 
butions are presented for plasma triglycerides in Figures 3 and 4. The points plotted in these figures represent the relative frequency of a 20-unit interval centered at the midpoint (i.e., points plotted at 130 represent the relative frequency of the interval 120 to 140 $\mathrm{mg} / \mathrm{dl})$. Frequencies for each ethnic group sum to $100 \%$.

The relative frequency distribution of plasma cholesterol for black males is shifted slightly to the right of that for white males $(P<0.0001$ ) (Fig. 1). For the 5737 white males and for the 1350 black males, mean values for plasma cholesterol were 155 and 162

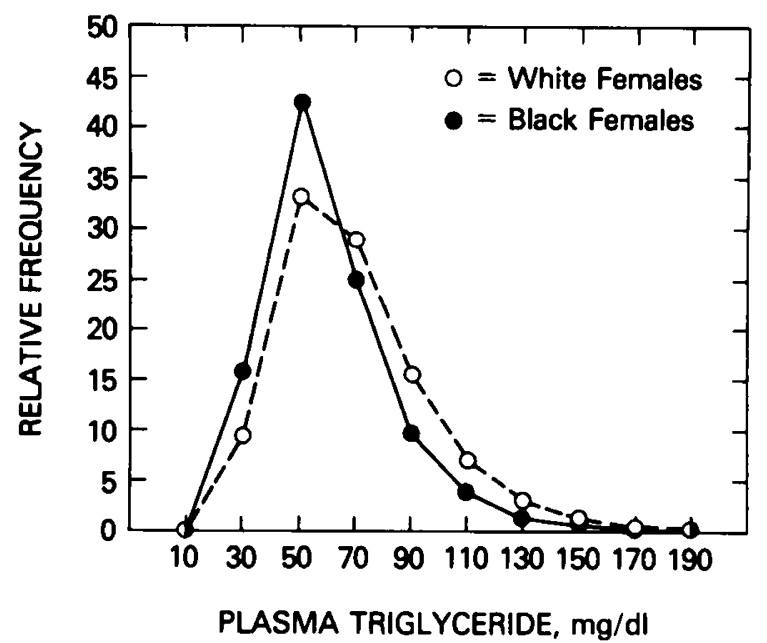

Fig. 4. Percentage of distribution of fasting triglyceride for white and black females.
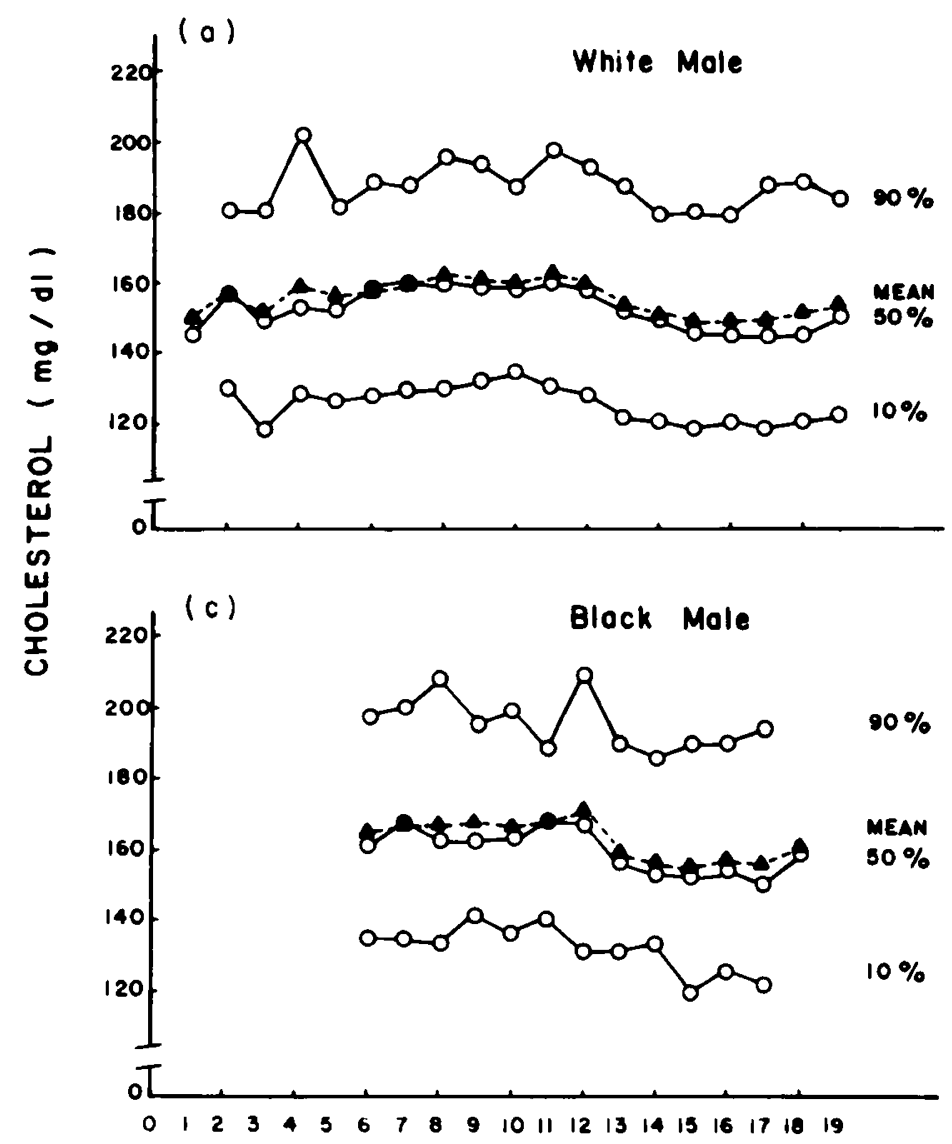

$\mathrm{mg} / \mathrm{dl}$, respectively. The distribution of plasma cholesterol for black females is similarly shifted to the right when compared to white females $(P<0.0001)$ (Fig. 2). Mean values for the 5288 white females and 1290 black females were 159 and $167 \mathrm{mg} / \mathrm{dl}$, respectively.

Conversely, the relative frequency distribution of plasma triglyceride for white males is shifted somewhat to the right of that for black males ( $P<0.0001$ ) (Fig. 3) with means for black and white males of 57 and $67 \mathrm{mg} / \mathrm{dl}$, respectively. Similarly, the triglyceride distribution for white females is shifted towards higher values than for black females. Mean values for black and white females were 61 and $70 \mathrm{mg} / \mathrm{dl}$, respectively, $P<0.0001$ (Fig. 4).

For the combined races (not shown), the distribution for females was generally higher for both triglyceride and cholesterol than for males $(P<0.0001)$.

\section{LIPID DISTRIBUTIONS BY AGE. RACE AND SEX}

Figures 5 to 6 and Tables 1 to 4 show the measures of central tendency (mean \pm S.D.) and selected positional values (percentiles) for cholesterol and triglyceride for white and black males and females by single year of age. The mean values tend to be slightly higher than the 50th percentile values, indicating a positive skewness of the distributions. This skewness is more apparent for the distribution of triglyceride than for cholesterol in all four of the race- and sex-specific subgroups.

\section{AGE-ASSOCIATED DIFFERENCES}

Cholesterol. Within the aggregated data, certain consistent ageassociated differences in plasma cholesterol occur. When the race-
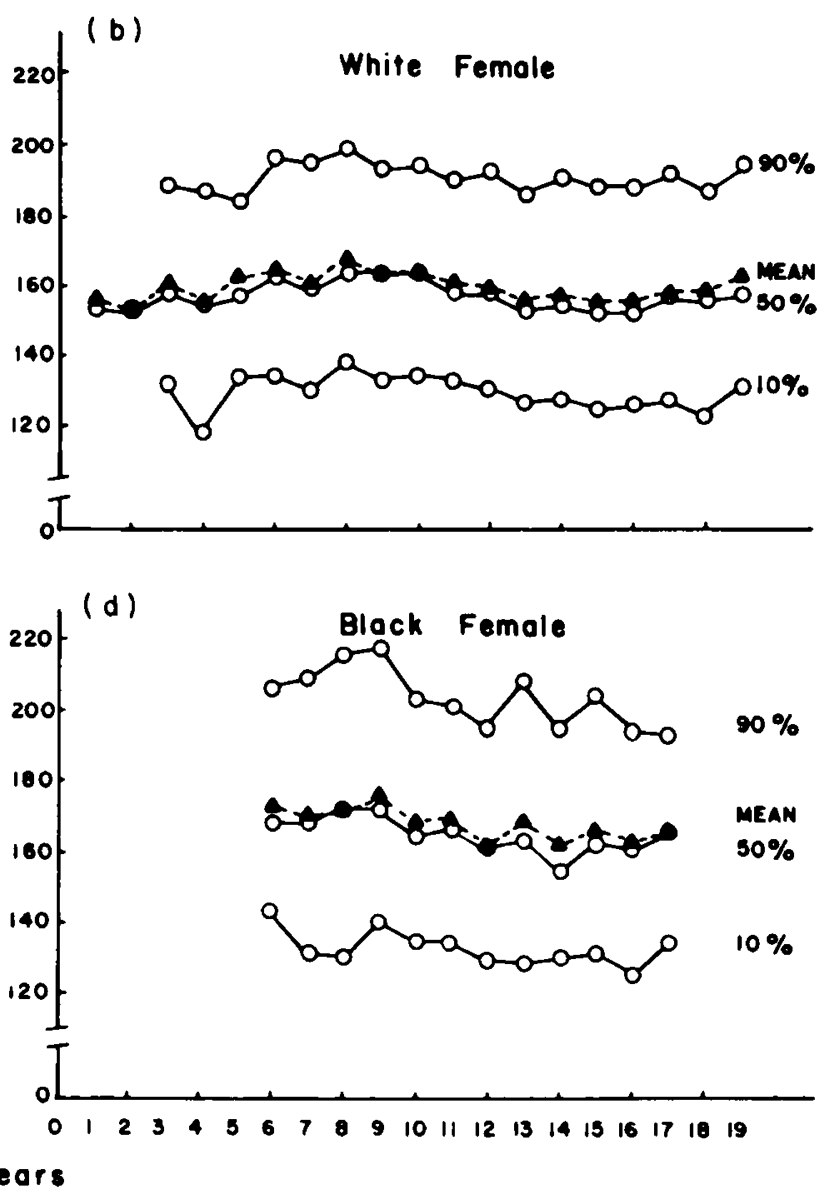

Fig. 5. Race- and sex-specific distributions of mean and percentile values of plasma cholesterol by age. 


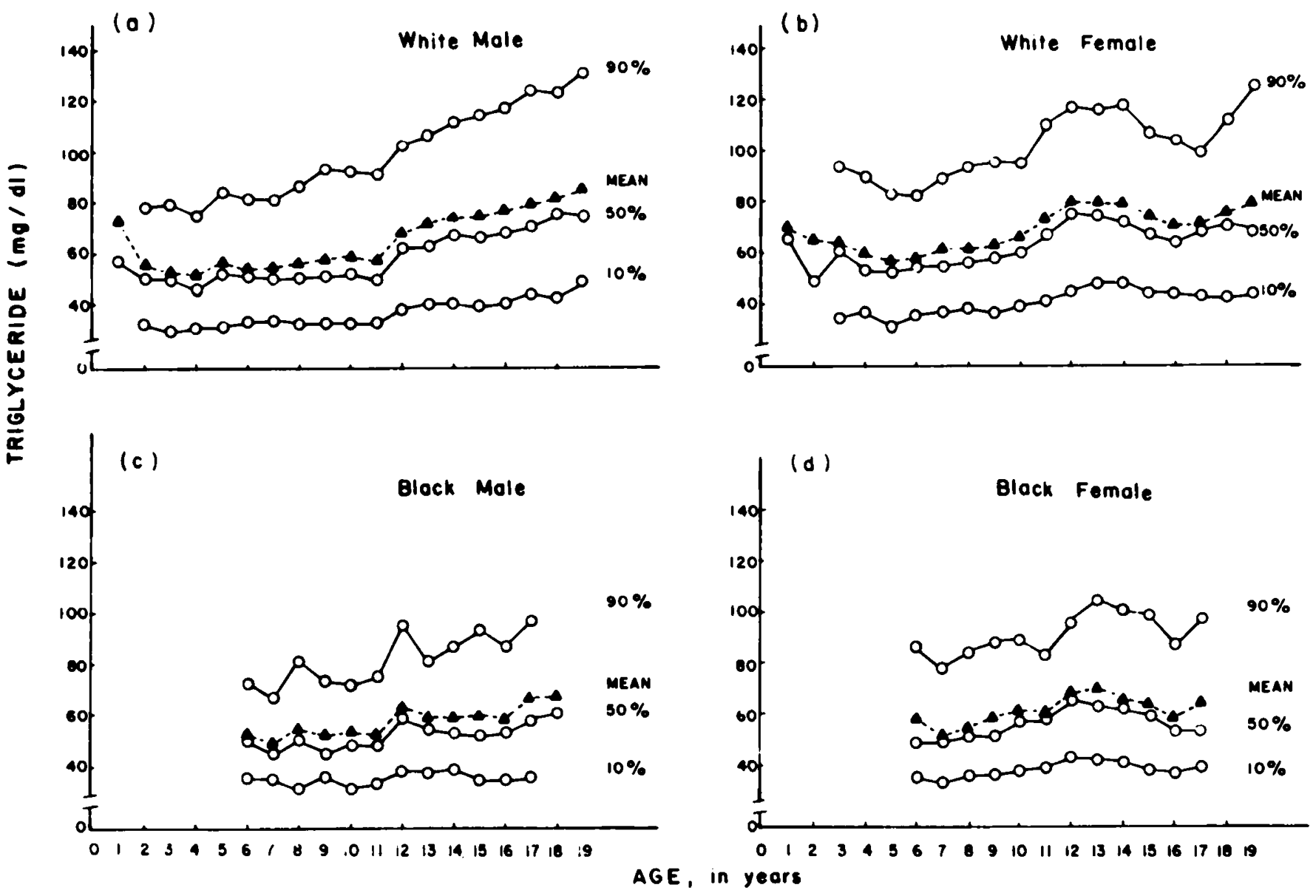

Fig. 6. Race- and sex-specific distributions of mean and percentile values of fasting triglyceride by age.

Table 1. Plasma cholesterol and plasma triglycerides: mean and percentile distribution for white males

\begin{tabular}{|c|c|c|c|c|c|c|c|c|c|c|c|c|c|c|c|c|c|c|c|c|}
\hline \multirow[b]{2}{*}{ Age' $^{\prime}$} & \multicolumn{10}{|c|}{ Cholesterol (mg/dl) } & \multicolumn{10}{|c|}{ Triglycerides, (mg/dl) } \\
\hline & $n^{2}$ & $\overline{\mathbf{x}}$ & S.D. & Sth & 10th & 25 th & soth & 75th & $90 \mathrm{th}$ & 95th & $n^{2}$ & $\overline{\mathbf{x}}$ & S.D. & 5th & $10 \mathrm{th}$ & $25 \mathrm{th}$ & Soth & 75th & 90th & 95th \\
\hline 0 & {$[10]$} & 143 & 29 & & & & & & & & {$[10]$} & 63 & 21 & & & & & & & \\
\hline I & [36] & 150 & 25 & & & 136 & 146 & 156 & & & {$[36]$} & 73 & 37 & & & 42 & 57 & 95 & & \\
\hline 2 & [49] & 158 & 22 & & & 140 & 158 & 173 & & & [49] & 55 & 22 & & & 40 & 51 & 67 & & \\
\hline 3 & 66 & 151 & 26 & 110 & 118 & 131 & 149 & 170 & 181 & 193 & 66 & 53 & 18 & 28 & 30 & 38 & 50 & 66 & 79 & 84 \\
\hline 4 & 77 & 159 & 31 & 115 & 128 & 139 & 154 & 175 & 203 & 221 & 77 & 52 & 20 & 29 & 31 & 38 & 47 & 57 & 75 & 89 \\
\hline 5 & 72 & 156 & 27 & 113 & 126 & 139 & 152 & 173 & 182 & 203 & 72 & 56 & 21 & 26 & 31 & 42 & 52 & 67 & 84 & 88 \\
\hline 6 & 278 & 158 & 24 & 120 & 128 & 141 & 158 & 174 & 189 & 201 & 278 & 54 & 19 & 31 & 33 & 40 & 51 & 64 & 81 & 96 \\
\hline 7 & 275 & 159 & 23 & 122 & 130 & 144 & 160 & 175 & 188 & 195 & 275 & 55 & 23 & 29 & 34 & 40 & $\underline{50}$ & 64 & 81 & 107 \\
\hline 8 & 332 & $\overline{162}$ & 29 & 121 & 130 & 144 & 160 & 177 & 196 & 206 & 332 & 56 & 23 & 29 & 33 & 40 & 50 & 65 & 86 & 101 \\
\hline 9 & 294 & 161 & 24 & 123 & 132 & 144 & 159 & 173 & 194 & 203 & 294 & 58 & 25 & 30 & 33 & 41 & 51 & 67 & 93 & 111 \\
\hline 10 & 455 & 159 & 21 & 127 & 135 & 145 & 158 & 173 & 188 & 196 & 455 & 58 & 25 & 29 & 33 & 41 & 52 & 68 & 92 & 105 \\
\hline 11 & 409 & 162 & 27 & 124 & $13 \mid$ & 144 & 160 & 177 & 198 & 211 & 409 & 57 & 25 & 29 & 33 & 40 & 50 & 68 & 91 & 106 \\
\hline 12 & 572 & 160 & 26 & 121 & 128 & 142 & 158 & 175 & 193 & 203 & 572 & 68 & 30 & 34 & 38 & 48 & 62 & 81 & 103 & 125 \\
\hline 13 & 411 & 153 & 26 & 115 & 122 & 135 & 152 & 170 & 188 & 195 & 411 & 71 & 36 & 35 & 40 & 48 & 63 & 83 & 107 & 143 \\
\hline 14 & 426 & 152 & 26 & 114 & 121 & 134 & 150 & 166 & 180 & 195 & 426 & 73 & 33 & 35 & 41 & 51 & 67 & 87 & 112 & 134 \\
\hline 15 & 508 & 149 & 26 & 111 & 119 & 130 & 146 & 165 & 181 & 194 & 508 & 74 & 35 & 34 & 40 & 52 & 66 & 87 & 115 & 134 \\
\hline 16 & 639 & 149 & 25 & 113 & 120 & 132 & 146 & 163 & 180 & 192 & 639 & 77 & 41 & 35 & 41 & 52 & 68 & 90 & 117 & 146 \\
\hline 17 & 417 & 150 & 27 & 110 & 119 & 131 & 146 & 165 & 188 & 204 & 417 & 79 & 38 & 39 & 44 & 55 & 70 & 89 & 124 & 160 \\
\hline 18 & 238 & 152 & 30 & 113 & 121 & 133 & 146 & 168 & 189 & 199 & 238 & 81 & 35 & 39 & 43 & 57 & 75 & 97 & 123 & 155 \\
\hline 19 & 173 & 154 & 26 & 114 & 123 & 137 & $|5|$ & 168 & 185 & 196 & 173 & 85 & 38 & 44 & 49 & 58 & 74 & 101 & 131 & 172 \\
\hline
\end{tabular}

'All ages, $n=5,737$.

${ }^{2}$ Where $n<50$ persons, $n$ is enclosed in brackets to denote that caution should be used in interpretation of the values presented. 
Table 2. Plasma cholesterol and plasma triglycerides: mean and percentile distribution for white females

\begin{tabular}{|c|c|c|c|c|c|c|c|c|c|c|c|c|c|c|c|c|c|c|c|c|}
\hline \multirow[b]{2}{*}{ Age' $^{\prime}$} & \multicolumn{10}{|c|}{ Cholesterol (mg/dl) } & \multicolumn{10}{|c|}{ Triglycerides, (mg/dl) } \\
\hline & $n^{2}$ & $\overline{\mathbf{x}}$ & S.D. & Sth & $10 \mathrm{th}$ & 25th & 50 th & 75th & 90th & 95th & $n^{2}$ & $\overline{\mathbf{x}}$ & S.D. & 5th & 10th & 25 th & 50 th & $75 \mathrm{th}$ & 90 th & 95th \\
\hline 0 & [6] & 148 & 36 & & & & & & & & [6] & 82 & 20 & & & & & & & \\
\hline 1 & [31] & 156 & 27 & & & 136 & 153 & 174 & & & [31] & 70 & 21 & & & 57 & 66 & 83 & & \\
\hline 2 & [33] & 152 & 25 & & & 137 & 153 & 166 & & & [33] & 65 & 31 & & & 42 & 49 & 71 & & \\
\hline 3 & 57 & 160 & 26 & 118 & 132 & 143 & 157 & 173 & 189 & 201 & 57 & 63 & 23 & 32 & 34 & 45 & 61 & 78 & 94 & 110 \\
\hline 4 & 59 & 155 & 28 & 108 & 118 & 136 & 155 & 176 & 187 & 196 & 59 & 59 & 22 & 34 & 37 & 45 & 53 & 68 & 90 & 94 \\
\hline 5 & 86 & 162 & 28 & 126 & 134 & 147 & 157 & 175 & 184 & 195 & 86 & 56 & 24 & 28 & 31 & 41 & 52 & 66 & 83 & 93 \\
\hline 6 & 253 & 165 & 24 & 129 & 134 & 145 & 163 & 183 & 196 & 205 & 253 & 57 & 21 & 32 & 36 & 43 & 54 & 65 & 82 & 95 \\
\hline 7 & 220 & 160 & 25 & 124 & 130 & 142 & 159 & 176 & 195 & 202 & 220 & 61 & 31 & 32 & 37 & 43 & 54 & 73 & 89 & 112 \\
\hline 8 & 297 & 166 & 24 & 129 & 139 & 147 & 164 & 182 & 199 & 209 & 297 & 61 & 24 & 34 & 38 & 44 & 56 & 71 & 93 & 104 \\
\hline 9 & 261 & 163 & 24 & 120 & 133 & 146 & 164 & 179 & 193 & 205 & 261 & 63 & 26 & 32 & 36 & 44 & 58 & 74 & 95 & 110 \\
\hline 10 & 417 & 163 & 25 & 127 & 134 & 146 & 163 & 177 & 194 & 205 & 417 & 66 & 28 & 35 & 39 & 48 & 60 & 76 & 95 & 116 \\
\hline 11 & 338 & 161 & 22 & 126 & 133 & 144 & 158 & 175 & 190 & 200 & 338 & 73 & 31 & 36 & 41 & 51 & 67 & 86 & 110 & 126 \\
\hline 12 & 536 & 161 & 24 & 124 & 131 & 144 & 158 & 175 & 192 & 203 & 536 & 79 & 30 & 38 & 45 & 58 & 75 & 96 & 117 & 132 \\
\hline 13 & 344 & 155 & 23 & 122 & 127 & 138 & 153 & 169 & 186 & 192 & 344 & 79 & 31 & 43 & 48 & 56 & 74 & 93 & 116 & 136 \\
\hline 14 & 441 & 157 & 25 & 120 & 128 & 142 & 155 & 171 & 191 & 198 & 441 & 79 & 32 & 38 & 48 & 58 & 72 & 92 & 117 & 138 \\
\hline 15 & 553 & 155 & 25 & 119 & 125 & 138 & 152 & 170 & 188 & 199 & 553 & 74 & 35 & 39 & 44 & 52 & 67 & 84 & 107 & 127 \\
\hline 16 & 675 & 155 & 27 & 121 & 126 & 139 & 152 & 168 & 188 & 197 & 675 & 71 & 31 & 37 & 44 & 52 & 64 & 82 & 104 & 120 \\
\hline 17 & 351 & 158 & 26 & 119 & 128 & 140 & 157 & 172 & 192 & 202 & 351 & 70 & 25 & 40 & 43 & 51 & 68 & 83 & 99 & 113 \\
\hline 18 & 193 & 157 & 25 & 116 & 123 & 140 & 156 & 172 & 187 & 199 & 193 & 75 & 29 & 39 & 42 & 56 & 70 & 87 & 112 & 126 \\
\hline 19 & 137 & 162 & 29 & 123 & 131 & 146 & 158 & 174 & 194 & 212 & 137 & 79 & 46 & 40 & 44 & 54 & 69 & 87 & 126 & 135 \\
\hline
\end{tabular}

'All ages, $n=5,288$.

${ }^{2}$ Where $n<50$ persons, $n$ is enclosed in brackets to denote that caution should be used in interpretation of the values presented.

Table 3. Plasma cholesterol and plasma triglycerides: mean and percentile distribution for black males

\begin{tabular}{|c|c|c|c|c|c|c|c|c|c|c|c|c|c|c|c|c|c|c|c|c|}
\hline \multirow[b]{2}{*}{$\mathrm{Age}^{\prime}$} & \multicolumn{10}{|c|}{ Cholesterol (mg/dl) } & \multicolumn{10}{|c|}{ Triglycerides, (mg/dl) } \\
\hline & $n^{2}$ & $\overline{\mathbf{x}}$ & S.D. & Sth & 10th & 25 th & 50 th & 75 th & $90 \mathrm{th}$ & 95th & $n^{2}$ & $\overline{\mathbf{x}}$ & S.D. & 5 th & 10th & 25 th & 50 th & 75 th & 90th & 95th \\
\hline 0 & {$[0]$} & & & & & & & & & & [0] & & & & & & & & & \\
\hline 1 & [2] & 139 & 38 & & & & & & & & [2] & 49 & 6 & & & & & & & \\
\hline 2 & [4] & 154 & 15 & & & & & & & & [4] & 52 & 24 & & & & & & & \\
\hline 3 & [8] & 149 & 34 & & & & & & & & [8] & 46 & 15 & & & & & & & \\
\hline 4 & [3] & 164 & 31 & & & & & & & & [3] & 64 & 39 & & & & & & & \\
\hline 5 & [8] & 166 & 33 & & & & & & & & {$[8]$} & 45 & 14 & & & & & & & \\
\hline 6 & 97 & 164 & 29 & 128 & 134 & 144 & 161 & 179 & 198 & 213 & 97 & 53 & 20 & 33 & 35 & 40 & 50 & 60 & 72 & 94 \\
\hline 7 & 52 & 167 & 26 & 116 & 134 & 149 & 167 & 181 & 200 & 208 & 52 & 49 & 13 & 33 & 34 & 38 & 45 & 56 & 67 & 75 \\
\hline 8 & 103 & 167 & 29 & 129 & 133 & 147 & 162 & 185 & 208 & 218 & 103 & 54 & 23 & 28 & 31 & 40 & 50 & 61 & 81 & 96 \\
\hline 9 & 74 & 168 & 23 & 135 & 141 & 150 & 162 & 185 & 195 & 200 & 74 & 53 & 18 & 33 & 36 & 41 & 45 & 62 & 73 & 81 \\
\hline 10 & 118 & 167 & 24 & 126 & 136 & 151 & 164 & 186 & 199 & 206 & 118 & 53 & 24 & 29 & 31 & 40 & 48 & 61 & 72 & 95 \\
\hline 11 & 68 & 167 & 22 & 133 & 140 & 153 & 168 & 178 & 189 & 191 & 68 & 52 & 18 & 30 & 33 & 37 & 47 & 65 & 75 & 81 \\
\hline 12 & 120 & 171 & 31 & 127 & 131 & 149 & 169 & 195 & 209 & 216 & 120 & 63 & 24 & 32 & 38 & 45 & 59 & 73 & 95 & 100 \\
\hline 13 & 88 & 159 & 23 & 124 & 131 & 144 & 156 & 174 & 190 & 195 & 88 & 58 & 25 & 33 & 37 & 43 & 54 & 66 & 81 & 90 \\
\hline 14 & 91 & 157 & 23 & 115 & 133 & 143 & 153 & 169 & 186 & 195 & 91 & 58 & 21 & 32 & 38 & 44 & 53 & 66 & 86 & 98 \\
\hline 15 & 138 & 154 & 28 & 110 & 120 & 135 & 152 & 172 & 190 & 200 & 138 & 59 & 26 & 28 & 35 & 41 & 52 & 68 & 94 & 97 \\
\hline 16 & 200 & 157 & 26 & 120 & 125 & 138 & 154 & 176 & 190 & 199 & 200 & 57 & 23 & 31 & 35 & 41 & 52 & 64 & 86 & 102 \\
\hline 17 & 126 & 156 & 28 & 118 & 122 & 137 & 150 & 173 & 194 & 208 & 126 & 65 & 36 & 32 & 35 & 45 & 57 & 73 & 97 & 122 \\
\hline 18 & [38] & 163 & 25 & & & 145 & 159 & 172 & & & [38] & 65 & 27 & & & 48 & 61 & 73 & & \\
\hline 19 & [12] & 160 & 22 & & & & & & & & [12] & 60 & 19 & & & & & & & \\
\hline
\end{tabular}

\footnotetext{
'All ages, $n=1,350$.
}

${ }^{2}$ Where $n<50$ persons, $n$ is enclosed in brackets to denote that caution should be used in interpretation of the values presented.

and sex-specific mean values for cholesterol are plotted for each year of age, the mean values for white males less than 11 years of age show no consistent pattern of differences by age (Table 1; Fig. 5). However, from $162 \mathrm{mg} / \mathrm{dl}$ at age 11 , mean values for cholesterol are successively lower in each group, reaching $149 \mathrm{mg} / \mathrm{dl}$ at age 15. The curve rises from age 16 , reaching $154 \mathrm{mg} / \mathrm{dl}$ at age 19 .

For black males, a similar pattern is observed (Table 3; Fig. 5). The cholesterol means are generally stable below age 11 . From $171 \mathrm{mg} / \mathrm{dl}$ at age 12 , however, values decline $15 \mathrm{mg} / \mathrm{dl}$ to 156 $\mathrm{mg} / \mathrm{dl}$ at age 17 .

For white females, the means for plasma cholesterol vary below age 7. A peak mean value of $166 \mathrm{mg} / \mathrm{dl}$ occurs at age 8 (Table 2; Fig. 5). Mean values for cholesterol vary betwen 155 and 158 for age 13 to 18 years and then rise to $162 \mathrm{mg} / \mathrm{dl}$ for age 19 .
Small sample sizes may account for the erratic variation in cholesterol means in black females during childhood (Table 4). However, from a mean of $176 \mathrm{mg} / \mathrm{dl}$ at age 9 , the means decrease irregularly to $161 \mathrm{mg} / \mathrm{dl}$ at age 12 . For the 13 to 19 year olds, the weighted average of the means is somewhat higher, $164 \mathrm{mg} / \mathrm{dl}$ (Table 4; Fig. 5), and the range is from 161 to $167 \mathrm{mg} / \mathrm{dl}$.

Triglyceride. The graph of the age distribution of mean values for plasma triglyceride (Fig. 6) is also curved for each race-sex group. For white males (Table 1), no consistent pattern of ageassociated differences for ages 3 to 11 is observed in the aggregated data for mean plasma triglyceride values. However, by age 12 , the mean triglyceride value reaches $68 \mathrm{mg} / \mathrm{dl}$, an increase of 11 from $57 \mathrm{mg} / \mathrm{dl}$ at age 11 . Then the mean is higher in each successive age group. For age 19, the mean value for triglyceride is $85 \mathrm{mg}$ / 
dl. Thus, during the age period 12 to 19 years, the age curve for plasma triglyceride rises in white males in contrast to the age curve for cholesterol.

For black males (Table 3; Fig. 6), the means for plasma triglyceride vary from 45 to $64 \mathrm{mg} / \mathrm{dl}$ for ages below 11 . As for white males, the mean values for plasma triglyceride then tend to increase. However, for black males, the increase in mean values for plasma triglycerides is not consistent throughout adolescence.

For white females (Table 2; Fig. 6), the mean value for plasma triglycerides is essentially stable ( 56 to $66 \mathrm{mg} / \mathrm{dl}$ ) from age 3 to 10 . For ages 12 to 14 , however, the mean value is $79 \mathrm{mg} / \mathrm{dl}$. Unlike that for white males, the age curve for mean values for plasma triglyceride in the white females does not continue to increase throughout adolescence, but falls to $70 \mathrm{mg} / \mathrm{dl}$ at age 17 and then increases again to the 12 to 14 year level $(79 \mathrm{mg} / \mathrm{dl})$ for age 19 years.

For black females (Table 4; Fig. 6), the mean values for plasma triglyceride are erratic for ages less than 6 years, probably reflecting the small number of observations. From ages 9 to 17, however, the mean values for plasma triglyceride range from 59 to $70 \mathrm{mg} /$ dl. In a pattern similar to that for white females, mean values for triglyceride for black females decline to $59 \mathrm{mg} / \mathrm{dl}$ by age 16 and then increase slightly for the 17 year olds. The numbers were not sufficient for stable estimates for the 18 and 19 year olds.

\section{DISCUSSION}

The large sample size, the biracial nature of the study populations, and the diversity of their geographical environments provide an extensive, well-defined, and consistently analyzed data base for study of lipids in children. The summary data on the distributions for cholesterol and triglyceride for the aggregate population ( $\mathrm{Ta}$ bles 1 to 4) should provide valuable information for the researcher, as well as the practitioner, for assessment of individual children relative to this population distribution. Conventionally, the 90 th or 95 th percentile has been used for identification of children with "elevated" cholesterol and triglyceride. These arbitrary cutpoints do not necessarily represent a threshold value for "disease" and are not necessarily an indication of need for further diagnostic maneuvers and therapy. By virtue of the phenomenon of regression towards the mean, some children initially identified at the
90 th or 95 th percentile for cholesterol and triglyceride will have on repetitive sampling levels below the upper cutpoints $(6,7)$.

Other problems inherent in the indiscriminant use of upper cutpoints and other statistics as threshold values for disease should also be considered. For example, the age-adjusted, race- and sexspecific mean values for $\mathrm{CH}$ and $\mathrm{TG}$ varies considerably among the LRC (Table 5). In clinical judgment, the magnitude of the clinic differences may not be of much practical importance; however, some of the differences among clinics are statistically significant (and will be the subject of later reports).

Although this analysis includes a very large number of children and adolescents (13,665), the number of persons in certain age, race, and sex groups was not large enough for calculation of reliable estimates. Where the value is based on less than 50 persons (denoted by brackets in the tables), the mean and selected percentiles are presented for completeness of information only; they are not offered as a clinical resource because they may be unstable estimates.

Generally, females had somewhat higher plasma cholesterol and triglyceride levels than males. These differences were small and may reflect the higher levels of LDL and VLDL lipoproteins in girls, as reported for the Bogalusa Study (38) and preliminary analysis of data for visit 2 of the LRC Prevalence Study $(34,42)$. If so, the direction of these childhood male-female differences in lipoproteins does not persist past early adulthood because adult males have been reported as having higher levels of LDL and

Table 5. Age-adjusted' clinic means for whites

\begin{tabular}{lccccc}
\hline & \multicolumn{2}{c}{ Males } & & \multicolumn{2}{c}{ Females } \\
\cline { 2 - 3 } \cline { 5 - 6 } & $\begin{array}{c}\text { Choles- } \\
\text { terol }\end{array}$ & $\begin{array}{c}\text { Triglyc- } \\
\text { eride }\end{array}$ & & $\begin{array}{c}\text { Choles- } \\
\text { terol }\end{array}$ & $\begin{array}{c}\text { Triglyc- } \\
\text { eride }\end{array}$ \\
\hline Baylor & 147 & 71 & & 156 & 70 \\
Cincinnati & 152 & 83 & & 156 & 78 \\
Johns Hopkins & 146 & 73 & & 153 & 71 \\
La Jolla & 154 & 66 & & 161 & 68 \\
Minnesota & 149 & 76 & & 157 & 77 \\
Toronto & 149 & 82 & & 157 & 82 \\
\hline
\end{tabular}

' Adjusted to age 15 by covariance analysis (37).

Table 4. Plasma cholesterol and plasma triglycerides: mean and percentile distribution for black females

\begin{tabular}{|c|c|c|c|c|c|c|c|c|c|c|c|c|c|c|c|c|c|c|c|c|}
\hline \multirow[b]{2}{*}{ Age' } & \multicolumn{10}{|c|}{ Cholesterol (mg/dl) } & \multicolumn{10}{|c|}{ (Triglycerides, mg/dl) } \\
\hline & $n^{2}$ & $\overline{\mathbf{x}}$ & S.D. & Sth & 10 th & 25 th & 50th & 75 th & 90 th & 95th & $n^{2}$ & $\overline{\mathbf{X}}$ & S.D. & 5 th & 10 th & 25 th & 50 th & $75 \mathrm{th}$ & 90th & 95th \\
\hline 0 & [2] & 124 & 33 & & & & & & & & [2] & 86 & 45 & & & & & & & \\
\hline 1 & {$[6]$} & 154 & 29 & & & & & & & & [6] & 52 & 18 & & & & & & & \\
\hline 2 & {$[5]$} & 160 & 19 & & & & & & & & [5] & 43 & 5 & & & & & & & \\
\hline 3 & {$[7]$} & 167 & 24 & & & & & & & & {$[7]$} & 51 & 10 & & & & & & & \\
\hline 4 & [4] & 147 & 17 & & & & & & & & [4] & 68 & 13 & & & & & & & \\
\hline 5 & {$[8]$} & 183 & 48 & & & & & & & & [8] & 51 & 10 & & & & & & & \\
\hline 6 & 102 & 172 & 24 & 138 & 143 & 152 & 169 & 185 & 206 & 216 & 102 & 57 & 29 & 29 & 35 & 41 & 49 & 64 & 86 & 108 \\
\hline 7 & 60 & 170 & 29 & 126 & 131 & 150 & 170 & 187 & 209 & 216 & 60 & 52 & 17 & 27 & 33 & 40 & 49 & 62 & 78 & 82 \\
\hline 8 & 100 & 172 & 31 & 124 & 130 & 145 & 172 & 194 & 215 & 226 & 100 & 54 & 19 & 31 & 35 & 40 & 51 & 63 & 84 & 90 \\
\hline 9 & 68 & 176 & 33 & 133 & 140 & 154 & 171 & 184 & 217 & 235 & 68 & 60 & 30 & 33 & 36 & 45 & 51 & 66 & 88 & 100 \\
\hline 10 & 131 & 169 & 30 & 128 & 134 & 148 & 164 & 187 & 203 & 211 & 131 & 60 & 20 & 36 & 38 & 45 & 57 & 70 & 89 & 97 \\
\hline 11 & 65 & 168 & 26 & 131 & 134 & 150 & 167 & 183 & 201 & 213 & 65 & 61 & 18 & 33 & 39 & 47 & 58 & 72 & 83 & 92 \\
\hline 12 & 128 & 161 & 26 & 121 & 129 & 142 & 161 & 177 & 195 & 203 & 128 & 68 & 22 & 37 & 43 & 51 & 65 & 79 & 96 & 109 \\
\hline 13 & 70 & 167 & 31 & 120 & 128 & 145 & 163 & 188 & 208 & 219 & 70 & 70 & 25 & 37 & 42 & 49 & 63 & 88 & 105 & 112 \\
\hline 14 & 80 & 161 & 29 & 120 & 130 & 139 & 154 & 180 & 195 & 205 & 80 & 66 & 24 & 38 & 41 & 49 & 62 & 74 & 101 & 110 \\
\hline 15 & 150 & 166 & 27 & 129 & 131 & 147 & 163 & 185 & 204 & 211 & 150 & 64 & 28 & 34 & 38 & 46 & 58 & 74 & 99 & 121 \\
\hline 16 & 192 & 162 & 27 & 120 & 125 & 142 & 161 & 179 & 194 & 206 & 192 & 59 & 24 & 32 & 36 & 43 & 54 & 68 & 87 & 95 \\
\hline 17 & 83 & 166 & 25 & 124 & 134 & 150 & 165 & 179 & 193 & 208 & 83 & 62 & 25 & 36 & 39 & 44 & 53 & 71 & 97 & 107 \\
\hline 18 & [23] & 167 & 28 & & & 144 & 165 & 86 & & & {$[23]$} & 66 & 35 & & & 42 & 54 & 70 & & \\
\hline 19 & {$[6]$} & 166 & 27 & & & & & & & & [6] & 55 & 18 & & & & & & & \\
\hline
\end{tabular}

' All ages, $n=1,290$.

${ }^{2}$ Where $n<50$ persons, $n$ is enclosed in brackets to denote that caution should be used in interpretation of the values presented. 
VLDL lipoproteins and lower levels of HDL lipoproteins than females $(5,17,34)$.

The sex-specific mean values for plasma cholesterol for blacks were higher than for whites at ages 6 to 19. Such differences are of considerable interest, and the magnitude of some differences is potentially of physiologic significance. These black-white differences are similar to those reported for 5 to 14-year-old school children in Bogalusa, LA where black children had higher HDL cholesterol levels, which accounted for their higher total cholesterol levels (38). However, in samples of umbilical cord blood, no significant black-white differences in HDL levels or in other lipid and lipoprotein constituents were reported (-12). The relative contributions of heredity and environment to black-white HDL differences remain to be further elucidated (43). A detailed analysis of pediatric black-white differences in regard to lipoproteins will be available in the near future from the LRC (visit 2) studies.

Conversely, the sex-specific mean values for fasting plasma triglyceride concentrations for whites were higher than for blacks at all age points. These ethnic differences are also of interest and similar to the Bogalusa reports (9). These findings are not unexpected because in population groups, triglyceride and VLDL cholesterol levels are inversely related to $\operatorname{HDL}(5,17)$. Thus, the finding that blacks have higher HDL cholesterol (38) and lower triglyceride levels than whites is consistent. Further assessment of these differences in triglyceride and HDL levels may be facilitated by forthcoming data on black-white differences in body size, obesity, and nutritional intake. Whether the modest black-white differences in cholesterol, triglyceride, and HDL levels have clinical significance (2) remains to be evaluated.

The third aspect of the aggregate data, the age-associated differences in mean values for cholesterol and triglyceride, was investigated. A general pattern of fairly stable mean values for plasma cholesterol for all age, sex, race groups is noted for ages under 11 years for males and for ages under 8 to 9 for females. Subsequently, for all groups, there is a gradual average decline of approximately $13 \mathrm{mg} / \mathrm{dl}$ in mean plasma cholesterol which continues through ages 15 to 16 for females and 16 to 17 for males and then is followed by a gradual increase by ages 18 and 19. For plasma triglycerides, from ages 3 to 11 for males and 3 to 9 for females, the mean values vary within a narrow range for all age, sex, and race groups, but at ages 11 to 12 , a gradual increase in plasma triglycerides is observed. For white males, this increase continues generally unabated throughout the teenage years. For females, the mean values for triglyceride increase to about age 13 , fall through ages 15 to 17 , and then increase. The interpretation of these data is clearly limited by the fact that this is a crosssectional, not a longitudinal, study. Cross-sectional data from several recent studies $(8,9,13,16,31,35)$ have shown similar age- associated differences in cholesterol and triglyceride levels. Longitudinal studies $(23,24,30)$ have also shown similar cholesterol and triglyceride changes in small cohorts.

Although the children studied in the LRC Prevalence Study are not a representative sample of a more general population, the information gathered should be useful and generalizable under reasonable constraints.

The age-associated differences in the magnitude and direction of triglyceride and cholesterol suggest a complex relationship between the variables age, sex, and race. Some of the largest age differences in lipid values occur around the time of pubescence and the adolescent spurts in height and weight, raising the possibility that the phenomena may be related. Concomitant hormonal changes may be more directly related.

The 95th percentile values for triglycerides and for cholesterol are considerably lower than previous National Heart, Lung, and Blood Institute standard cutpoints for 0 to 19 years: $230 \mathrm{mg} / \mathrm{dl}$ for total plasma cholesterol and $140 \mathrm{mg} / \mathrm{dl}$ for triglyceride $(25)$. These lower cholesterol values may reflect differing laboratory methods or the downward trend in plasma cholesterol values observed in a sample of the United States population (32). The overall effect of new standards based on these LRC findings will be to increase estimates of the prevalence of "hyper" and lipidemia in children. Only for black females of age 9 do these values exceed the previous NHLBI standard of $230 \mathrm{mg} / \mathrm{dl}$ for cholesterol. Only for white males aged $13,16,17,18$ and 19 do these 95 th percentiles exceed the previous National Heart, Lung, and Blood Institute standard of $140 \mathrm{mg} / \mathrm{dl}$ for triglyceride.

No large-scale longitudinal study has followed changes in lipids and lipoproteins in population cohorts throughout adolescence and into young adulthood. Longitudinal studies are, however, underway at the Bogalusa and Muscatine Specialized Centers of Research and at the Cincinnati LRC. These prospective data may clarify the relation between levels of sex hormones and plasma lipids and lipoproteins.

Longitudinal assessment of children at all deciles of the distribution for cholesterol and triglyceride may provide important information on "tracking." Ability to predict that a child will remain in an elevated decile for cholesterol and/or triglyceride may be relevant for prediction of risk for coronary heart disease. If, in fact, children with elevated values for coronary heart disease risk factors tend to retain these increased values over time, as has been suggested by preliminary data $(6,44)$, then identification of pediatric hyperlipidemia may be an important first step in the prevention of the atherosclerotic process $(10,22)$. The possible long-term significance of elevated levels of cardiovascular "risk factors" detected in children cannot be evaluated until results from longitudinal studies of childhood cohorts are available.

\section{LIPID RESEARCH CLINICS}

\section{NORTH AMERICAN CLINICS}

Baylor College of Medicine, Houston, Texas

Director: William Insull, M.D.

Past Director: Antonio Gotto, M.D.

* George Washington University, Washington, D.C. Director: John LaRosa, M.D.

Johns Hopkins University, Baltimore, Maryland

Director: Peter Kwiterovich, M.D.

Oklahoma Medical Research Foundation, Oklahoma City, Oklahoma

Director: Reagan Bradford, M.D.
Stanford University, Palo Alto, California

Director: John Farquhar, M.D.

University of California at San Diego, La Jolla, California

Director: Daniel Steinberg, M.D.

Acting Director: John Turner, M.D.

Past Director: Virgil Brown, M.D.

University of Cincinnati, Cincinnati, Ohio Director: Charles Glueck, M.D.

University of Iowa, Iowa City, Iowa

Director: Francois Abboud, M.D.

Past Director: William Connor, M.D. 
University of Minnesota, Minneapolis, Minnesota

Director: Ivan D. Frantz, Jr., M.D.

University of Toronto and McMaster University at Toronto and Hamilton,

respectively, Ontario, Canada

Director: Alick Little, M.D.

Co-Directors: Maurice Mishkel, M.D. and George Steiner, M.D.
University of Washington, Seattle, Washington

Director: William Hazzard, M.D.

Acting Director: Robert Knopp, M.D.

Past Director: Edward Bierman, M.D.

* Washington University, St. Louis, Missouri

Director: Gustav Schonfeld, M.D.

Past Director: Robert Shank, M.D.

\section{USSR CLINICS}

All-Union Cardiological Research Center, Moscow

Director: Elena Gerasimova, M.D.
Institute of Experimental Medicine, Leningrad

Director: Anatoli Klimov, M.D.

\section{ISRAELI CLINIC}

Hadassah Medical School and Hebrew University, Jerusalem

Director: Yechezkiel Stein, M.D.

\section{SUPPORT AGENCIES}

Central Clinical Chemistry Laboratory

Bio-Science Laboratories, Van Nuys, California

Director: Frank Ibbott, Ph.D.

Past Director: Donald Wybenga, B.M.

Central Electrocardiographic Laboratory

University of Alabama, Birmingham, Alabama

Director: L. Thomas Sheffield, M.D.

Central Patient Registry and Coordinating Center

University of North Carolina, Chapel Hill, North Carolina

Director: O. Dale Williams, Ph.D.

Past Director: James E. Grizzle, Ph.D.
* Drug Supply and Distribution Center

Mead Johnson, Evansville, Indiana

Director: John Boenigk, Ph.D.

Lipid Standardization Laboratory

Center for Disease Control, Atlanta, Georgia

Director: Gerald Copper, M.D., Ph.D.

Nutrition Coding Center

University of Minnesota, Minneapolis, Minnesota

Director: P. Victro Grambsch

\section{PROGRAM OFFICE}

Lipid Metabolism Branch, National Heart, Lung, and Blood Institute

Chief: Basil Rifkind, M.D.

Past Chief: Robert Levy, M.D.
Past Prevalence Study Coordinators:

Gary Fisher, M.D.;

Barry Greenberg

Robin Harris, M.P.H.

\section{LRC EPIDEMIOLOGY COMMITTEE}

Chairperson: H.A. Tyroler, M.D.

Paul Anderson, Ph.D.; Elizabeth Barrett-Connor, M.D.; Mary Brockway, Ph.D.; Gary Chase, Ph.D.; Bobbe Christensen Ph.D.; Michael Criqui, M.D.; Michael Davies, M.D.; Alexander Deev, Ph.D.; Ido deGroot, M.P.H.: Manning Feinleib, M.D.; Marian Fisher, Ph.D.; Igor Glasunov, M.D.; Gaetan Godin, M.S.; S.T. Halfon, M.D.; Robin Harris, M.P.H.; William Haskell, Ph.D.; Gerardo Heiss, M.D., Ph.D.; David Hewitt, M.A.; Judith Hill,

\section{REFERENCES AND NOTES}

I. Ahmed. S.. Lippel. K.. Bachorik. P., Albers. J.. Williams, J., and Cooper, G. Analytical performance and comparability of the determination of triglycerides by 12 lipid research clinics. Clin. Chem.. 24(2): 330 (1978).

2. Atherosclerosis Study Group and Epidemiology Study Group of the Inter-Society Commission for Heart Disease Resources: primary prevention of the atherosclerotic diseases. Circulation. 42: A55 (1979).

3. Bachorik, P., Cooper, G. R., Lippel, K., and Ahmed, S.: Standardization of cholesterol and triglyceride measurements by twelve lipid research clinics; protides of the Biological Fluids. In: H. Peeters: Proceedings of the 25th Colloquium. pp. 307-314 (Pergammon Press, New York, 1978).

4. Carlson. L. A., and Böttiger, L. E. Ischemic heart disease in relation to fasting values of plasma triglycerides and cholesterol. Lancet. 2: 865 (1972).

5. Castelli. W. P.. Doyle. J. T.. Gordon. T.. Hames, C. G., Hjortland, M. C.. Hulley. S. B.. Kagan. A... and Zukel. W. J. HDL cholesterol and other lipids in coronary heart disease. Cooperative lipoprotein phenotyping study. Circulation, 55: 767 (1977).

6. Clarke. W., Woolson. R.. Schrott. H.. Wiebe. D.. and Lauer. R.: Tracking of blood pressure, serum lipids and obesity in children: the Muscatine study. Circulation (Abstract). 54 (Suppl. 3): 11. (1976).
M.S.; Joanne Hoover, M.D.; David Jacobs, Ph.D.; Kathe Kelly, M.S.; Alick Little, M.D.; Arden Mackenthun, Ph.D.; Irma Mebane, M.S.; Richard Mowery, M.S.P.H.; John Morrison, Ph.D.; John B. O'Sullivan, M.D.; Basil Rifkind, M.D.; Carl Rubenstein, M.D.; William J. Schull, Ph.D.; Dimitri Shestov, M.D.; Israel Tamir, M.D.; Henry Taylor, Ph.D.; Pearl Van Natta, Ph.D.; Robert Wallace, M.D.; O. Dale Williams, Ph.D.; Andrei Zadoja, M.D.

7. Ederer. F.: Serum cholesterol changes: effect of diet and regression toward the mean. J. Chronic Dis.. 25: 277 (1972).

8. Ellefson, R. D., Elveback, L. R., Hodgson. P. A., and Wiedman, W. H. Cholesterol and triglycerides in lipoproteins in young persons in Rochester. Minnesota. Mayo Clin. Proc.. 53: 307 (1978).

9. Frerichs. R. R.. Srinivasan. S. R., Webber. L. S.. and Berenson. G. S.: Serum cholesterol and triglyceride levels in 3.446 children of a biracial community: the Bogalusa heart study. Circulation. 54: 302 (1976).

10. Glueck. C. J., Fallat. R. W., and Tsang. R. C.: Hypercholesterolemia and hypertriglyceridemia in children: a pediatric approach to primary atherosclerosis prevention. Am. J. Dis. Child., 128: 569 (1974).

11. Glueck, C. J., Fallat, R. W., Tsang, R. C., Buncher, C. R.: Hyperlipidemia in progeny parents with myocardial infarction before age 50. Am. J. Dis. Child. 127: 70 (1974)

12. Glueck, C. J., Gartside, P. S., Tsang. R. C., Mellies, M., and Steiner. P. M. Black-white similarities in cord blood. lipids and lipoproteins. Metabolism. 26 : 347 (1977).

13. Godfrey. R. C.. Stenhouse. N. S.. Cullen. K. J., Blackman. V. Cholesterol and the child: studies of the cholesterol levels of Busselton school children and their parents. Aust. Paediatr. J., 8: 72 (1972).

14. Goldstein. J. L., and Brown, M. S.: The low-density lipoprotein pathway and its relation to atherosclerosis. Ann. Rev. Biochem., 46: 897 (1977). 
15. Goldstein, J. L., Schrott. H. G.. Hazzard, W. R., Bierman, E. L., and Motulsky, A. G.: Hyperlipidemia in coronary heart disease. II. Genetic analysis of lipid levels in 176 families and delineation of a new inherited disorder, combined hyperlipidemia. J. Clin. Invest.. 52: 1544 (1973).

16. Golubjatnikov. R.. Paskey. T.. and Inhorn. S. L.: Serum cholesterol levels of Mexican and Wisconsin school children. Am. J. Epidemiol., 96: 36 (1972)

17. Gordon. T., Castelli. W. P.. Hjortland. M. C.. Kannel. W. B., and Dawber. T. R.: High density lipoprotein as a protective factor against coronary heart disease: the Framingham study. Am. J. Med., 62: 707 (1977).

18. Hennekens. C. H.. Jesse. M. J.. Klein. B. E., Gourley, J. E., and Blumenthal, S. Cholesterol among children of men with myocardial infarction. Pediatrics, 58 . 211 (1976).

19. Kannel, W. B.: The role of cholesterol in coronary atherogenesis. Med. Clin. N. A., $58: 363$ (1974).

20. Keys. A.: Coronary heart disease-the global problem. Atherosclerosis, 22: 149 (1975).

21. Kuller. L. H.: Epidemiology of cardiovascular diseases: current perspectives. Am. J. Epidemiol.. 104: 425 (1976).

22. Kwiterovich, P. O.. Jr.: Pediatric aspects of hyperlipoproteinemia. In: B. Rifkind, R. I. Levy Hyperlipidemia, Diagnosis and Therapy. pp. 249-280. (Grune and Stratton, New York, 1977)

23. Lauer. R. M.. Connor. W. E., Leaverton. P. E., Reiter, M. A., and Clarke. W. R Coronary heart disease risk factors in school children: the Muscatine study. J. Pediatr.. 86: 697 (1975).

24. Lee, A. V.: Individual trends in total serum cholesterol of children and adolescents over a ten year period. Am. J. Clin. Nutr., 20: 5 (1967).

25. Lipid Research Clinics Program: Reference Manual for Lipid Research Clinics Program Prevalence Study. Vols. I and 2. Central Patient Registry and Coordinating Center for the Lipid Research Clinics, Dept. of Biostatistics (Univ. of North Carolina. Chapel Hill, 1974).

26. Lipid Research Clinics Program, Epidemiology Committee: Plasma lipid distributions in 11 selected North American populations. Submitted to Circulation, 1978.

27. Lipid Research Clinics Program: Manual of Laboratory Operations, Vol. 1. Lipid and Lipoprotein Analysis, DHEW Publication No. (NIH) 76-628. (U.S. Government Printing Office, Washington, D.C., 1974).

28. Lippel, K.. Ahmed, S.. Albers. J.. Jr.. Bachorik. P.. Cooper, G., Helms, R., and Williams, J.: Analytical performance and comparability of the determination of cholesterol by 12 lipid research clinics. Clin. Chem., 23: 1744 (1977).

29. Miller. G. J., and Miller.N. E.: Plasma high density lipoprotein concentrations and development of ischemic heart disease. Lancet. I: 16 (1975).

30. Milligan. C. A., Wilcox. E. B., and Galloway. L. S.: Serum cholesterol and physical characteristics of pre-adolescents and adolescents. J. Am. Diet. Assoc. 49: 309 (1966).

31. National Center for Health Statistics: Serum cholesterol levels of children 4-17 years of age. United States, 1971-1974. Vital and Health Statistics. Series 11 (Advance Data No. 8) Health Resources Administration. Department of Health, Education, and Welfare, Rockville, MD. (1977).

32. National Center for Health Statistics: Total serum cholesterol levels of adults 18 74 years: United States, 1971-1974. Vital and Health Statistics. Series 11. No. 205. Department of Health. Education, and Welfare Publication. No. (PHS) 78-1652. April 1978.

33. Rhoads, C. G.. Gulbrandsen. C. L.. and Kagan. A.: Serum lipoproteins and coronary heart disease in a population of Hawaii-Japanese men. N. Engl. J. Med.. 294: 293 (1976).

34. Rifkind, B. M., Tamir, I., and Heiss, G.: Preliminary high density lipoprotein findings.: The Lipid Research Clinics Program. In: A. M. Gotto, N. E. Miller, and M. S. Oliver: High Density Lipoproteins and Atherosclerosis. pp. 109-119. (Elsevier-Amsterdam. New York. 1978).

35. Savage, P. J.. Hamman, R. F., Bartha, G., Dippe, S. E.. Miller, M., and Bennett. P. H.: Serum cholesterol levels in American Pima Indian children and adolescents. Pediatrics, 58: 274 (1976).

36. Siegel S.: Nonparametric Statistics. pp. 127-136 (McGraw-Hill Book Company, New York. 1956).

37. Snedecor, G. W., and Cochran, W. G.: Statistical Methods pp. 349-35I. (Iowa State University Press, Ames, Iowa. 1967).

38. Srinivasan, S. R.. Frerichs, R. R.. Webber. L. S.. and Berenson. G. S.: Serum lipoprotein profile in children from a biracial community: the Bogalusa heart study. Circulation. 54: 309 (1976).

39. Stamler. J.: Epidemiology of coronary heart disease. Med. Clin. N. Am., 57: 5 (1973).

40. Stamler, J.: Lifestyles, major risk factors, proof, and public policy. Circulation, 58: 3 (1978).

41. Tamir, 1., Bojanower, Y., Levtow, O., Heldenberg, D., Dickerman, Z., and Werbin, B.: Serum lipids and lipoproteins in children from families with early coronary heart disease. Arch. Dis. Child., 47: 808 (1972).

42. Tamir, I., Heiss, G., Glueck, C. J., Christensen, B., Kwiterovich, P., and Rifkind, B. M.: Lipid and lipoprotein distributions in white children ages 6-19 years. The Lipid Research Clinics Program Prevalence Study. Submitted to Pediatrics. Sept. 1978.

43. Tyroler, H. A.. Hames, C. G., Krishan, I., Heyden. S., Cooper, G., and Cassel, J. C.: Black-white differences in serum lipids and lipoproteins in Evans County. Prev. Med.. 4: 541 (1975).

44. Webber. L. S.. Frerichs, R. R.. Voors. A. W.. and Berenson, G. S.: Clustering of risk factor variables at high levels in children. Circulation (Abstract). 56 (Suppl.): 111 (1977).

45. Zilversmit, D. B.: Mechanisms of cholesterol accumulation in the arterial walls. Am. J. Cardiol., 35: 559 (1975).

46. Signed informed consent was obtained for each participant and the protocols were approved by each institution's Committee for the Protection of Human Subjects.

47. Members of the Pediatric Working Group of the LRC Program are: Bobbe Christensen. PhD., chairperson: Gary Chase. Ph.D.; I. deGroot, M.P.H.: Charles Glueck. M.D.: Robin Harris, M.P.H.: Gerardo Heiss, M.D.: Peter Kwiterovich. M.D.: Darwin Labarthe, M.D.: and Israel Tamir, M.D.

The seven Lipid Research Clinics that included children and adolescents in their target populations for the LRC Prevalence Study are: Baylor College of Medicine. Houston, Texas: The Johns Hopkins University. Baltimore. Maryland: Oklahoma Medical Research Foundation, Oklahoma City. Oklahoma: University of California at San Diego, La Jolla, California: University of Cincinnati. Cincinnati, Ohio: University of Minnesota. Minneapolis. Minnesota: University of Toronto (Toronto. Ontario) and McMaster University (Hamilton. Ontario)

48. Requests for reprints should be addressed to: Dr. Basil Rifkind, Lipid Metabolism Branch, National Heart, Lung, and Blood Institute, NIH Federal Building, Room 302, Bethesda, MD. 20014 (USA).

49. This research was supported by the Lipid Research Clinics Program of the Lipid Metabolism Branch of the National Heart. Lung, and Blood Institute. Contracts NO1-HVI-2156-L, N01-HV3-2961-L, NOI-HV1-2160-L, N01-HV22914-L. N0I-HVI-2158-L. N0I-HV2-2915-L. NOI-HVI-2243-L. NOI-HV22932-L. and NOI-HV2-2917-L.

50. Received for publication Oct. 10, 1978.

51. Accepted for publication April 26, 1979. 